\title{
Classification of childhood asthma phenotypes and long-term clinical responses to inhaled anti- inflammatory medications
}

\section{Citation}

Howrylak, Judie A., Anne L. Fuhlbrigge, Robert C. Strunk, Robert S. Zeiger, Scott T. Weiss, and Benjamin A. Raby. 2014. Classification of childhood asthma phenotypes and long-term clinical responses to inhaled anti-inflammatory medications. Journal of Allergy and Clinical Immunology 133, no. 5: 1289-1300.e12. doi:10.1016/j.jaci.2014.02.006.

\section{Published Version}

doi:10.1016/j.jaci.2014.02.006

\section{Permanent link}

http://nrs.harvard.edu/urn-3:HUL.InstRepos:27005898

\section{Terms of Use}

This article was downloaded from Harvard University's DASH repository, and is made available under the terms and conditions applicable to Open Access Policy Articles, as set forth at http:// nrs.harvard.edu/urn-3:HUL.InstRepos:dash.current.terms-of-use\#OAP

\section{Share Your Story}

The Harvard community has made this article openly available.

Please share how this access benefits you. Submit a story.

Accessibility 
Published in final edited form as:

J Allergy Clin Immunol. 2014 May ; 133(5): 1289-130112.

\title{
Classification of childhood asthma phenotypes and long-term clinical responses to inhaled anti-inflammatory medications
}

\author{
Judie A. Howrylak, MDa, Anne L. Fuhlbrigge, MD ${ }^{b, c, d}$, Robert C. Strunk, MD ${ }^{\mathrm{e}}$, Robert S. \\ Zeiger, MD ${ }^{f}$, Scott T. Weiss, MD ${ }^{b, c, d}$, and Benjamin A. Raby, MD ${ }^{b, c, d}$ for the Childhood \\ Asthma Management Program Research Group* \\ aDivision of Pulmonary, Allergy and Critical Care Medicine, Department of Medicine, Penn State \\ Milton S. Hershey Medical Center, Hershey \\ ${ }^{b}$ Channing Division of Network Medicine, Department of Medicine, Brigham and Women's \\ Hospital, Boston \\ 'Division of Pulmonary and Critical Care Medicine, Department of Medicine, Brigham and \\ Women's Hospital, Boston \\ dHarvard Medical School, Boston \\ eDivision of Allergy and Pulmonary Medicine, Department of Pediatrics, Washington University \\ School of Medicine and St Louis Children's Hospital, San Diego \\ fDepartment of Pediatrics, University of California-San Diego, and Allergy Department Kaiser \\ Permanente, San Diego
}

\section{Abstract}

Background-Although recent studies have identified the presence of phenotypic clusters in asthmatic patients, the clinical significance and temporal stability of these clusters have not been explored.

Objective-Our aim was to examine the clinical relevance and temporal stability of phenotypic clusters in children with asthma.

Methods-We applied spectral clustering to clinical data from 1041 children with asthma participating in the Childhood Asthma Management Program. Posttreatment randomization

(C) 2014 American Academy of Allergy, Asthma \& Immunology

Corresponding author: Benjamin A. Raby, MD, Channing Division of Network Medicine, Brigham and Women's Hospital and Harvard Medical School, 181 Longwood Ave, Boston, MA 02115. rebar@ channing.harvard.edu.

* Members of the Childhood Asthma Management Program Research Group are listed in the acknowledgments section.

This article is subject to the NIH Public Access Policy (http://publicaccess.nih.gov).

Disclosure of potential conflict of interest: A. L. Fuhlbrigge has received research support from the National Heart, Lung, and Blood Institute (NHLBI) and the Agency for Healthcare and Research Quality and has received personal fees from GlaxoSmithKline, Merck, Icon Medical Imaging, Lovelace Respiratory Research Institute, Scientific Therapeutics, and the American Academy of Allergy, Asthma \& Immunology. R. S. Zeiger has received research support from the NHLBI, Genentech, GlaxoSmithKline, Aerocrine, Merck, MedImmune, and Thermo Fisher; is on the Research Advisory Board for DBV Technologies; has consultant arrangements with GlaxoSmithKline, Genentech, Novartis, the NHLBI/Penn State, Aerocrine, and AstraZeneca; and has stock/stock options in DBV Technologies. S. T. Weiss has consultant arrangements with Novartis. The rest of the authors declare that they have no relevant conflicts of interest. 
follow-up data collected over 48 months were used to determine the effect of these clusters on pulmonary function and treatment response to inhaled anti-inflammatory medication.

Results-We found 5 reproducible patient clusters that could be differentiated on the basis of 3 groups of features: atopic burden, degree of airway obstruction, and history of exacerbation. Cluster grouping predicted long-term asthma control, as measured by the need for oral prednisone $(P<.0001)$ or additional controller medications $(P=.001)$, as well as longitudinal differences in pulmonary function $(P<.0001)$. We also found that the 2 clusters with the highest rates of exacerbation had different responses to inhaled corticosteroids when compared with the other clusters. One cluster demonstrated a positive response to both budesonide $(P=.02)$ and nedocromil $(P=.01)$ compared with placebo, whereas the other cluster demonstrated minimal responses to both budesonide $(P=.12)$ and nedocromil $(P=.56)$ compared with placebo.

Conclusion-Phenotypic clustering can be used to identify longitudinally consistent and clinically relevant patient subgroups, with implications for targeted therapeutic strategies and clinical trials design.

\section{Keywords}

Childhood asthma; asthma phenotypes; inhaled corticosteroids; cluster analysis; asthma classification; longitudinal study

Asthma is characterized by chronic airway inflammation, airways hyperresponsiveness, and reversible airflow limitation. ${ }^{1}$ The Global Initiative for Asthma guidelines ${ }^{2}$ and multiple large-scale clinical trials ${ }^{3-5}$ have helped to guide current evidence-based treatments. The current stepwise therapeutic approach is designed to maximize the overall level of asthma control and medication adherence while minimizing treatment cost and adverse side effects. However, it has been observed that subsets of asthmatic children not only respond differently to medications ${ }^{6-8}$ but also exhibit markedly different disease trajectories, with some children outgrowing their asthma by early adolescence and others having disease progression ${ }^{9-12}$ or decreased lung function in adulthood. ${ }^{13}$ The lack of distinct histologic features or reliable quantitative biomarkers suggests that asthma might represent a collection of diverse disorders with distinct causes and natural histories. Such heterogeneity poses significant clinical challenges, particularly in regard to long-term prognostication and treatment decision making.

Numerous classification schemes have been proposed to account for this heterogeneity. ${ }^{8,14-16}$ Although tailored treatment strategies are suggested for patients with distinct forms of disease, most classification schemes have limited utility in guiding management strategies or reliably predicting long-term morbidity. Recognition of these limitations has motivated the development of multivariate models that consider many patient characteristics simultaneously. ${ }^{17-19}$ More recently, newer data generation procedures that leverage sophisticated statistical approaches have been applied to large asthma cohorts, with early success in defining previously unrecognized clusters of asthmatic patients. ${ }^{20-22}$ However, these studies were limited by their lack of prospective follow-up data, precluding assessment of the utility of these classification schemes in informing treatment decisions or disease prognostication. 
It is in this context that we present the results of a phenotype-based cluster analysis of asthmatic children aged 5 to 12 years who participated in the 48-month Childhood Asthma Management Program (CAMP) trial ${ }^{3,23}$ and demonstrate that computational approaches can define meaningful clusters with both longitudinal consistency and differing responses to medical therapy.

\section{METHODS}

\section{Study population}

The CAMP study design and primary outcomes have been described. ${ }^{3,23}$ Subjects aged 5 to 12 years were eligible if they (1) had a history of mild-to-moderate persistent asthma defined by the presence of symptoms at least twice weekly, the use of an inhaled bronchodilator at least twice weekly, or the use of daily medication for asthma; (2) had greater than 7 days of symptoms or decreased peak expiratory flow rates during the 28-day run-in period when taking only albuterol as needed; (3) exhibited airway hyperresponsiveness to methacholine; and (4) had no other clinically significant conditions. Participants were randomized to receive $200 \mu \mathrm{g}$ of budesonide twice daily $(\mathrm{n}=311$; Pulmicort; AstraZeneca, Westborough, Mass), $8 \mathrm{mg}$ of nedocromil sodium ( $\mathrm{n}=312$; Tilade; Rhone-Poulenc Rorer, Collegeville, Pa), or matching placebo $(n=418)$. Subjects were evaluated every 4 months for 48 months. Asthma exacerbations were treated with short courses of oral prednisone. The addition of beclomethasone dipropionate (168 $\mu \mathrm{g}$ twice daily; Vanceril, Schering-Plough, Kenilworth, NJ) was allowed if asthma control was inadequate. If control remained unsatisfactory, replacement or additional medications were allowed.

\section{Variable selection}

Asthma history interviews were conducted before and spirometry and methacholine challenge testing were performed after a 28-day screening period off all anti-inflammatory asthma medications. From an initial list of 48 clinical variables (see Table E1 in this article's Online Repository at www.jacionline.org), we selected 18 variables as representative of each child's objective risk factors for increased asthma burden as inputs for the clustering algorithm. We excluded several clinical variables that were included in prior cluster analysis studies, including asthma symptoms. These symptom variables were purposely excluded from the model for several reasons, including the following: (1) asthma symptoms were not evaluated as an outcome in the original CAMP study, (2) descriptions of asthma symptoms were obtained from daily symptom diaries maintained by study participants and subject to reporting bias, and (3) there was increased variability in the response rate and number of missing values for the symptoms described in the diaries.

Also, in contrast to prior cluster analyses, potential asthma risk factors, such as sex, ethnicity, and environmental exposure, were purposely excluded from cluster model building. Our rationale for excluding this demographic information was our desire to test the hypothesis that sex and ethnic factors play a role in the pathogenesis of childhood asthma. Cluster analysis provided the opportunity to evaluate the segregation of these variables independent of the model-building process. For this reason, we excluded sex and ethnicity 
for our model and instead included hypothesis testing of these variables after building the phenotypic clusters.

\section{Cluster analysis}

We used spectral clustering to perform cluster analysis. ${ }^{24}$ In recognition that clustering is dependent on user-defined inputs, we used an iterative approach over a range of clusters (1 cluster up to a maximum of 8 clusters) to define the optimal number of clusters to form. For each iteration, cluster centers were generated by means of random sampling of the data eigenvector matrix. We used the gap statistic to select the optimal number of clusters. The gap statistic reflects the difference between within-cluster dispersion and that expected under an appropriate null distribution. ${ }^{25}$ Further details of the cluster-building methodology are provided in the Methods section in this article's Online Repository at www.jacionline.org.

\section{Statistical analysis of phenotypic clusters}

We explored between-cluster differences in baseline clinical, demographic, and environmental covariates that were not included in the original model by using KruskalWallis and $\chi^{2}$ tests and used Kaplan-Meier estimates of cumulative probability and Cox proportional hazards models to evaluate 2 prospective outcomes, including time to first course of prednisone and time to initiation of alternate antiasthma therapies. We used linear mixed-effects models to examine between-cluster differences in prospective measures of lung function and $\mathrm{PC}_{20}$.

\section{RESULTS}

\section{Cluster analysis}

The baseline characteristics for all 1041 participants are presented in Table E2 in this article's Online Repository at www.jacionline.org. As previously reported, ${ }^{23}$ the demographic composition of the CAMP cohort is consistent with that of patients with childhood asthma in North America, including a higher proportion of boys, early age of onset, and high prevalence of atopic features.

We performed spectral clustering of 18 baseline phenotypic characteristics and optimized our model selection by calculating a gap statistic for different clustering models. Our results demonstrated 5 distinct phenotypic clusters.

All but 5 of the variables included in the final model were distributed differentially across clusters (Table I). Despite their prominence in previously described asthma classification schemes, ${ }^{20-22}$ no between-cluster differences were observed in this study for anthropomorphic measures or circulating leukocyte levels (Table I).

\section{Phenotypic characterization of asthma clusters}

The essential features of each cluster can be characterized with respect to 3 groups of factors: (1) atopic burden (prevalence of atopic dermatitis (AD), allergic rhinitis or skin reactivity, and total serum IgE and circulating eosinophil levels); (2) lung function and 
airway lability (prebronchodilator $\mathrm{FEV}_{1}, \mathrm{FEV}_{1}$ /forced vital capacity [FVC] ratio, bronchodilator response, and methacholine airways hyperresponsiveness $\left.\left[\mathrm{PC}_{20}\right]\right)$; and (3) baseline exacerbation history (prior hospitalization and emergency department [ED] visits; Box 1). From these groupings, we constructed an Atopy-Obstruction-Exacerbation (AOE) scoring scheme, assigning low, medium, or high scores for each factor group (Table I). For clarity of subsequent discussion, although prospective long-term asthma control was not considered in the clustering procedures (only baseline variables were considered), the cluster groups are also numbered in ascending rank order of poor long-term asthma control (ie, $1=$ best control and $5=$ worst control, as defined by need for oral steroid therapy during the 48 months of follow-up observation, see below).

\section{Box 1}

\section{Summary of clinical characteristics of asthma clusters (AOE classification)}

Cluster 1: Mild asthma with low atopy, obstruction, and exacerbation rate (LLL)

- $\quad$ Largest subgroup of patients (28.8\%)

- No history of $\mathrm{AD}$, lowest prevalence of hay fever or skin prick test reactivity, lowest IgE levels

- Preserved lung function (highest $\mathrm{FEV}_{1} / \mathrm{FVC}$ ratio)

- Lowest bronchodilator response, intermediate airway hyperresponsiveness

- No prior hospitalization for asthma and lowest reported prevalence of ED visits

- Lowest risk of exacerbation ${ }^{*}$

Cluster 2: Atopic asthma with low levels of obstruction and medium rates of exacerbation (HLL)

- Universally report $\mathrm{AD}$, high prevalence of allergic rhinitis and skin test reactivity

- Preserved lung function (highest $\mathrm{FEV}_{1}$ )

- Intermediate bronchodilator response and airways hyperresponsiveness

- No prior hospitalization, low rates of prior ED visits

- Low-to-intermediate risk of exacerbations*

\section{Cluster 3: Atopic asthma with high levels of obstruction and medium rates of exacerbation (HHM)}

- Rarely report AD (in contrast to HLM cluster) but highest prevalence of allergic rhinitis and skin test reactivity

- Most reduced lung function (lowest $\mathrm{FEV}_{1}$ and $\mathrm{FEV}_{1} / \mathrm{FVC}$ ratio)

- High bronchodilator response and most severe airways hyperresponsiveness

- Few prior hospitalizations but intermediate rates of prior ED visits (similar to HLM cluster) 
- Intermediate risk of exacerbations*

\section{Cluster 4: Moderately atopic asthma with high levels of obstruction and high exacerbation rates (MHH)}

- No history of $\mathrm{AD}$, intermediate prevalence of hay fever (52.9\%), lower IgE levels

- Reduced lung function (low $\mathrm{FEV}_{1} / \mathrm{FVC}$ ratio, similar to $\mathrm{HHH}$ cluster)

- High bronchodilator response and high airways hyperresponsiveness

- Most reports of prior hospitalization

- Intermediate-to-high risk of exacerbation*

\section{Cluster 5: Highly atopic asthma with high levels of obstruction and high exacerbation rates $(\mathrm{HHH})$}

- Smallest subgroup of patients $(9.3 \%)$

- Nearly universal AD, highest prevalence of skin test reactivity, highest IgE levels, highest eosinophilia, intermediate prevalence of allergic rhinitis

- Reduced lung function (low $\mathrm{FEV}_{1} / \mathrm{FVC}$ ratio, similar to MHH cluster)

- Highest bronchodilator response and severe airways hyperresponsiveness

- Most reports of prior hospitalization and highest rate of ED visits

- Highest risk of exacerbation*

*Poor long-term asthma exacerbation risk is defined from prospective survival analysis of time to first course of oral prednisone. This variable was derived by using the defined cluster groupings and was therefore not considered in spectral cluster analyses used to define the clusters.

The largest group of patients (cluster 1, 28.8\% of cohort) represents the mildest cases with the fewest prior exacerbations, the lowest prevalence of atopic features, and preserved lung function (AOE classification LLL). The smallest cluster, cluster 5 (9.3\%), consists of the most severe cases with the highest report of prior exacerbation, a very high atopic burden, and reduced lung function (AOE group $\mathrm{HHH}$ ). The 3 remaining clusters reflect subsets with intermediate levels of severity and more heterogeneous clinical features. Cluster 2 (19.3\%) includes those subjects with high atopic burden but preserved lung function (relative to the other groups) and intermediate airways hyperresponsiveness. This group has a low baseline ED visit rate and no reports of prior hospitalization (AOE group HLL). Patients in cluster 3 (20.9\%) have high atopy burden, the most compromised lung function, and extreme airways hyperresponsiveness but have intermediate ED visit rates and only 1 report of prior hospitalization (AOE group HHM). In contrast, although patients in cluster 4 (21.6\%) are substantially less atopic than those in cluster 2 and have reduced lung function at levels similar to those in cluster 3, they report higher ED visit rates, and nearly all report prior hospitalization for asthma (AOE group MHH). It is clear that no single feature is sufficient to characterize these groups. 
When we developed the phenotypic clusters, we did not include multiple demographic, environmental, and symptom variables in the development of our model. However, we explored the presence of between-cluster differences for these variables and found that with the exception of age, for which statistically significant differences were observed across cluster groups, demographic variables, including sex and socioeconomic indicators, did not differ. This finding differed from previously reported cluster analyses, which found between-cluster differences in demographic variables. Details of these findings are reported in the Results section in this article's Online Repository at www.jacionline.org.

\section{Temporal stability of phenotypic clusters}

We evaluated the temporal stability of the phenotypic clusters by assessing longitudinal differences in exacerbation rates and multiple measures of pulmonary function between different clusters. We assessed the clinical and prognostic relevance of the derived cluster designations by performing survival analysis of time to asthma exacerbation over 48 months of follow-up. Because the original CAMP study involved the randomization of medical therapies, we were able to make an unbiased assessment of between-cluster differences in response to treatment. Kaplan-Meier analysis confirmed that cluster grouping was predictive of time to the first course of oral prednisone ( $\log$-rank $P<.0001 ;$ Fig $1, A)$ and time to initiation of additional asthma controller therapy $(P<.0001$; Fig 1, $B)$. Within the first 12 months after randomization, in clusters 4 and 5 a minority of subjects (34\% [95\% CI, 29\% to $42 \%$ ] and $36 \%$ [95\% CI, 25\% to 44\%], respectively) had not required at least 1 course of oral steroids compared with $44 \%$ ( $95 \%$ CI, $38 \%$ to $51 \%$ ) and $46 \%$ (95\% CI, 39\% to 52\%) of subjects in clusters 3 and 2 and 54\% (95\% CI, 48\% to 60\%) of subjects in cluster 1 . These established trends persisted for the remainder of the trial, with greater separation of cluster groupings over time. At 4 years, the 2 most extreme groups exhibited a 3 -fold difference in their lack of requirement for oral prednisone (32\% [95\% CI, 27\% to 37\%] in cluster 1 vs $11 \%$ [95\% CI, $5 \%$ to $18 \%]$ in cluster $5, P<.0001)$. Similar relationships were noted for time to initiation of additional asthma controller therapies (Fig 1,B).

With 4 years of prospective follow-up as part of the CAMP clinical trial, we were able to assess the longitudinal consistency in airway hyperresponsiveness and pulmonary function across the 5 identified clusters using linear mixed-effects models. For methacholine $\mathrm{PC}_{20}$, prebronchodilator and postbronchodilator $\mathrm{FEV}_{1}$, and prebronchodilator and postbronchodilator $\mathrm{FEV}_{1} / \mathrm{FVC}$ ratio, we observed statistically significant $(P<.0001)$ between-cluster differences across time (Fig 2). Values for methacholine $\mathrm{PC}_{20}, \mathrm{FEV}_{1}$, and $\mathrm{FEV}_{1} / \mathrm{FVC}$ ratio demonstrated similar temporal patterns, with cluster 3 (HHM) having relatively lower values than cluster 1 (LLL) across time and minimal overlap in the trajectories of the clusters with the most extreme values. These temporal differences are aligned with baseline assessment of airway obstruction (Table I) and differ from baseline assessments of exacerbation rates, where cluster $5(\mathrm{HHH})$ had the highest rate of exacerbations and cluster 1 (LLL) had the lowest rate. 


\section{Cluster grouping correlates with prospective long-term asthma control and response to specific inhaled anti-inflammatory controller medications}

We next assessed whether treatment response to specific inhaled anti-inflammatory controller medications differed by cluster group. As originally reported in the primary outcomes assessment of the CAMP trial, ${ }^{3}$ use of inhaled budesonide significantly reduced the number of asthma exacerbations compared with placebo in all phenotypic clusters. A further finding was that nedocromil did not significantly reduce exacerbation rates or additional controller therapies compared with placebo. However, in a post hoc evaluation stratified by cluster grouping, we observed heterogeneity in treatment response rates to both medications (Fig 3 and Table II; and see Table E3 in this article's Online Repository at www.jacionline.org). We found that subjects stratified to the 3 more mild clusters (clusters 1,2 , and 3) demonstrated treatment response patterns similar to those reported in the cohort as a whole. However, in the 2 most severe clusters (clusters 4 and 5), we found that the therapeutic efficacy of nedocromil appeared to be more similar to that of budesonide. Subjects in cluster 4, those with the lowest atopic burden, worst lung function, and high baseline exacerbation rates, demonstrated a significant reduction in exacerbation rates when randomized to nedocromil (1.7-fold [95\% CI, 1.4-fold to 2.2-fold] reduction compared with placebo at 12 months and 1.6-fold [95\% CI, 1.1-fold to 1.6-fold] reduction at 4 years) that was similar (log-rank $P=.96$ for difference) to the reductions observed among those randomized to budesonide (1.6-fold [95\% CI, 1.3-fold to 2.0-fold] reduction compared with placebo at 12 months and 1.4-fold [95\% CI, 1.0-fold to 1.5 -fold] reduction at 4 years). For subjects in cluster 5, those with a high atopic burden, low lung function, and the highest baseline exacerbations, there was no decrease in exacerbation rates for subjects randomized to either nedocromil or budesonide (compared with placebo; $\log$-rank $P=.56$ and .12 , respectively).

\section{Comparisons with previously reported cluster groupings of asthma}

To assess the generalizability of our cluster analysis, we compared our results with those of 2 prior cluster analyses of subjects from the Severe Asthma Research Program (SARP) cohort, one in a pediatric population ${ }^{20}$ and one in a cohort of pediatric and adult subjects. ${ }^{22}$ Although both the SARP study and current study used unsupervised multivariate statistical methods for cluster determination, the variables included in the initial clustering model were different. The SARP studies included a mixture of both demographic and disease descriptive variables, whereas the current study included only disease descriptive variables in the initial model. In addition, the CAMP cohort was the only one that controlled for the use of inhaled corticosteroids (Table III), allowing for a formal test of differential response to therapy between clusters.

The asthma subgroups defined by both the SARP childhood study and the current CAMP study were similar with respect to the degree of atopy, airway obstruction, and exacerbation rates present within each of the subgroups (Table III). However, several differences exist between the 2 studies, including the absence in the SARP cohorts of a cluster with a low degree of atopy and a high degree of both airway obstruction and exacerbation rates (cluster 4 in the CAMP study). 
Furthermore, differences in the degree of atopy between clusters are more pronounced in the CAMP cohort than the SARP cohorts. For example, for the CAMP clusters, there are multiple clusters in which almost $100 \%$ of the subjects have a history of AD (cluster 2, 100\%; cluster 5, 97.9\%) and multiple clusters in which almost none of the subjects have a history of AD (cluster 1, $0 \%$; cluster 4, $0 \%$; cluster 3, $0.1 \%$ ). For the SARP clusters, the difference in the history of $\mathrm{AD}$ is comparatively less, with within-cluster incidence ranging from $47 \%$ to $72 \%$. In addition, the degree of spread for the serum IgE variable is different between the SARP and CAMP clusters, with a greater degree of spread present among the CAMP clusters when compared with the SARP clusters (234-645 vs 105-405 kU/L, respectively).

There are also many similarities between the CAMP clusters and the clusters generated from a cluster analysis of adults from the SARP study. Similar to the CAMP and childhood SARP clusters, the mixed adult and pediatric SARP clusters are comparable with respect to the degree of airway obstruction and exacerbation rates present within the clusters (Table III). However, the SARP clusters with a higher proportion of adults differ from both the CAMP and childhood SARP clusters in that the overall degree of atopy present, as determined by serum IgE level, is less for the adult than the childhood populations. The lowest IgE level for the childhood clusters ( $105 \mathrm{kU} / \mathrm{L}$ for childhood SARP cluster 1$)$ is almost as high as the highest IgE level for the adult clusters (141 kU/L for adult SARP cluster 1). Additionally, the degree of airway obstruction present in the adult population is much greater in the adult population, with $\mathrm{FEV}_{1} / \mathrm{FVC}$ ratios for each cluster ranging from 0.57 to 0.78 in the adult population versus 0.78 to 0.82 in the CAMP and 0.72 to 0.82 in the childhood SARP populations.

\section{DISCUSSION}

The clinical heterogeneity of asthma has motivated the use of machine-learning algorithms for the classification of patients using data-driven unbiased criteria. Although earlier work ${ }^{20-22}$ established the feasibility of this approach, many important questions remain unaddressed, including issues of reproducibility, generalizability, and clinical relevance. Without longitudinal follow-up, which was unavailable in prior reports, it is unclear whether the defined clusters have clinical utility. It is in this context that the results of our phenotypic clustering efforts and longitudinal analysis can be summarized.

First, we demonstrate the longitudinal consistency of our phenotypic clusters. When we developed the clusters, we limited ourselves to the clinical data obtained during baseline assessment of CAMP participants. Next, we evaluated for changes in cluster membership over the 48-month study period and found remarkable consistency in phenotypic distributions over time, particularly with regard to airway hyperresponsiveness, obstruction, and exacerbation rates. These findings echo those of a recent longitudinal cluster analysis that found membership in phenotypic clusters to be extremely stable over time. ${ }^{26} \mathrm{An}$ additional finding of our study was that different inhaled anti-inflammatory medications appeared to have no statistically significant effect on cluster membership over time, suggesting that although these medications might affect day-to-day symptoms, they have minimal effect on the natural history of childhood asthma. 
Second, we demonstrate the therapeutic benefit of our phenotypic clusters. We found important between-cluster differences in response to inhaled asthma therapies, with one cluster (cluster 4) showing decreased rates of exacerbations with both budesonide and nedocromil therapy and another cluster (cluster 5) showing poor response with both budesonide and nedocromil therapy. Our data suggest that although inhaled corticosteroids, such as budesonide, should serve as the primary treatment choice for asthma control in children with mild-to-moderate asthma, there are several subgroups of patients, including those with the poorest level of baseline asthma control, who appear to respond to nedocromil at levels similar to budesonide. Given safety concerns, particularly in children, regarding the long-term exposure to inhaled glucocorticoid therapy, identification of phenotypic clusters that could benefit similarly from nonsteroidal therapies would be of great value. Although the retrospective nature of the current study and the small size of several of the clusters limits our ability to draw firm clinical conclusions about the current results, our findings serve as the foundation for future prospective clinical trials investigating personalized responses to inhaled anti-inflammatory medications.

Finally, despite notable differences in the compositions of the patient populations, the computational algorithms used, and the variables considered in generating the clusters, our results show remarkable consistency with those obtained in the pediatric and adult SARP populations, both with respect to the number of phenotypic clusters identified (5-6 clusters in CAMP and SARP cohorts) and the characteristics of individual clusters. ${ }^{20-22}$ The similarity of our phenotypic clusters to those of other cohorts provides further evidence for the potential generalizability of clustering as a method of phenotyping asthmatic patients. Observed differences in the degree of atopy and airway obstruction present in the pediatric compared with adult clusters lend further support to the hypothesis of etiologic differences between childhood and adult asthma.

Our study had several limitations. First, we evaluated only children, and reports have shown that pediatric and adult asthma might represent 2 different disease states with different pathogenic mechanisms and natural histories. ${ }^{27}$ For this reason, the clinical implications of this cluster analysis might not be widely applicable to an adult asthmatic population.

Second, our study did not include patients with severe childhood asthma. Because our original population was ascertained for the purposes of a clinical trial, it included children with mild-to-moderate persistent asthma and specifically excluded those with more severe asthma. Thus there is a possibility that there is a severe childhood asthmatic phenotypic that was missed with our analysis, although the strong similarities in observed clusters with the childhood SARP study (which included a broader spectrum of disease severity) provide reassurance that the results of our cluster analysis are more widely applicable.

Third, the conclusions that we can draw from the clinical outcomes of our clusters are limited because of their small sample size and modest differences. For example, the children in cluster 5 had a limited response to inhaled budesonide and nedocromil compared with placebo, suggesting that the children in this cluster might have some resistance to corticosteroid therapy. However, because there were only 96 children in this cluster, we were underpowered to draw more clinically meaningful conclusions from this particular 
analysis. It will be necessary to validate some of these preliminary findings in future prospective studies to determine whether the children in this cluster are truly steroid resistant.

In conclusion, our results support the use of computationally inferred phenotypic classifications of asthma as having clinical utility. These models define subsets of patients with unique clinical attributes, discrete clinical trajectories, and variable responsiveness to antiasthma controller medications. Recognition of these clusters and their clinical relevance should motivate novel strategies in both the research and clinical settings. More refined phenotypic classification might better inform treatment decisions: as suggested by the results of our treatment responsiveness analysis, cluster assignment identifies 2 subsets of patients who respond similarly to both budesonide and nedocromil, providing clinicians with viable treatment options for patients at risk for corticosteroid-related complications. The observed between-cluster differences in environmental and genetic factors suggest that important etiologic differences underlie the configuration of different asthma subgroups. Future studies that consider more homogenous subsets of patients should improve research precision in characterizing the genetic and environmental causes. Thus in addition to helping inform clinical management, these more refined phenotypic classification schemes should help accelerate research efforts in defining the molecular and environmental underpinnings of this complex airways disease.

\section{Supplementary Material}

Refer to Web version on PubMed Central for supplementary material.

\section{Acknowledgments}

The Childhood Asthma Management Program is supported by contracts NO1-HR-16044, 16045, 16046, 16047, $16048,16049,16050,16051$, and 16052 with the National Heart, Lung, and Blood Institute (NHLBI) and General Clinical Research Center grants M01RR00051, M01RR0099718-24, M01RR02719-14, and RR00036 from the National Center for Research Resources. B.A.R. is supported by NHLBI/National Institutes of Health grants R01-086601, R01-093076, and RC2-HL101543.

\section{Abbreviations used}

$\begin{array}{ll}\text { AD } & \text { Atopic dermatitis } \\ \text { AOE } & \text { Atopy-Obstruction-Exacerbation } \\ \text { CAMP } & \text { Childhood Asthma Management Program } \\ \text { ED } & \text { Emergency department } \\ \text { FVC } & \text { Forced vital capacity } \\ \text { SARP } & \text { Severe Asthma Research Program }\end{array}$

\section{References}

1. National Asthma Education and Prevention Program: expert panel report III: guidelines for the diagnosis and management of asthma. Bethesda: National Heart, Lung, and Blood Institute; 2007. 
2. Bateman ED, Hurd SS, Barnes PJ, Bousquet J, Drazen JM, FitzGerald M, et al. Global strategy for asthma management and prevention: GINA executive summary. Eur Respir J. 2008; 31:143-78. [PubMed: 18166595]

3. The Childhood Asthma Management Program Research Group. Long-term effects of budesonide or nedocromil in children with asthma. N Engl J Med. 2000; 343:1054-63. [PubMed: 11027739]

4. Sorkness CA, Lemanske RF Jr, Mauger DT, Boehmer SJ, Chinchilli VM, Martinez FD, et al. Longterm comparison of 3 controller regimens for mild-moderate persistent childhood asthma: the Pediatric Asthma Controller Trial. J Allergy Clin Immunol. 2007; 119:64-72. [PubMed: 17140647]

5. Lemanske RF Jr, Mauger DT, Sorkness CA, Jackson DJ, Boehmer SJ, Martinez FD, et al. Step-up therapy for children with uncontrolled asthma receiving inhaled corticosteroids. N Engl J Med. 2010; 362:975-85. [PubMed: 20197425]

6. Szefler SJ, Phillips BR, Martinez FD, Chinchilli VM, Lemanske RF, Strunk RC, et al. Characterization of within-subject responses to fluticasone and montelukast in childhood asthma. J Allergy Clin Immunol. 2005; 115:233-42. [PubMed: 15696076]

7. Szefler S, Leung D. Glucocorticoid-resistant asthma: pathogenesis and clinical implications for management. Eur Respir J. 1997; 10:1640-7. [PubMed: 9230260]

8. Pavord ID, Brightling CE, Woltmann G, Wardlaw AJ. Non-eosinophilic corticosteroid unresponsive asthma. Lancet. 1999; 353:2213-4. [PubMed: 10392993]

9. Phelan P, Robertson C, Olinsky A. The Melbourne Asthma Study: 1964-1999. J Allergy Clin Immunol. 2002; 109:189-94. [PubMed: 11842286]

10. Kelly W, Hudson I, Raven J, Phelan P, Pain M, Olinsky A. Childhood asthma and adult lung function. Am Rev Respir Dis. 1988; 138:26-30. [PubMed: 3059867]

11. Oswald H, Phelan PD, Lanigan A, Hibbert M, Carlin JB, Bowes G, et al. Childhood asthma and lung function in mid-adult life. Pediatr Pulmonol. 1997; 23:14-20. [PubMed: 9035194]

12. Sears MR, Greene JM, Willan AR, Wiecek EM, Taylor DR, Flannery EM, et al. A longitudinal, population-based, cohort study of childhood asthma followed to adulthood. N Engl J Med. 2003; 349:1414-22. [PubMed: 14534334]

13. Strunk R, Weiss S, Yates K, Tonascia J, Zeiger R, Szefler S. Mild to moderate asthma affects lung growth in children and adolescents. J Allergy Clin Immunol. 2006; 118:1040-7. [PubMed: 17088127]

14. Romanet-Manent S, Charpin D, Magnan A, Lanteaume A, Vervloet D, Group EC. Allergic vs nonallergic asthma: what makes the difference? Allergy. 2002; 57:607-13. [PubMed: 12100301]

15. Colice G, Burgt J, Song J, Stampone P, Thompson P. Categorizing asthma severity. Am J Respir Crit Care Med. 1999; 160:1962-7. [PubMed: 10588614]

16. Corrao WM, Braman SS, Irwin RS. Chronic cough as the sole presenting manifestation of bronchial asthma. N Engl J Med. 1979; 300:633-7. [PubMed: 763286]

17. Covar RA, Strunk R, Zeiger RS, Wilson LA, Liu AH, Weiss S, et al. Predictors of remitting, periodic, and persistent childhood asthma. J Allergy Clin Immunol. 2010; 125:359-66. [PubMed: 20159245]

18. Forno E, Fuhlbrigge A, Soto-Quirós ME, Avila L, Raby BA, Brehm J, et al. Risk factors and predictive clinical scores for asthma exacerbations in childhood. Chest. 2010; 138:1156-65. [PubMed: 20472862]

19. Haselkorn T, Zeiger RS, Chipps BE, Mink DR, Szefler SJ, Simons FE, et al. Recent asthma exacerbations predict future exacerbations in children with severe or difficult-to-treat asthma. $\mathrm{J}$ Allergy Clin Immunol. 2009; 124:921-7. [PubMed: 19895984]

20. Fitzpatrick AM, Teague WG, Meyers DA, Peters SP, Li X, Li H, et al. Heterogeneity of severe asthma in childhood: confirmation by cluster analysis of children in the National Institutes of Health/National Heart, Lung, and Blood Institute Severe Asthma Research Program. J Allergy Clin Immunol. 2011; 127:382-9. [PubMed: 21195471]

21. Haldar P, Pavord ID, Shaw DE, Berry MA, Thomas M, Brightling CE, et al. Cluster analysis and clinical asthma phenotypes. Am J Respir Crit Care Med. 2008; 178:218-24. [PubMed: 18480428]

22. Moore WC, Meyers DA, Wenzel SE, Teague WG, Li H, Li X, et al. Identification of asthma phenotypes using cluster analysis in the Severe Asthma Research Program. Am J Respir Crit Care Med. 2010; 181:315-23. [PubMed: 19892860] 
23. Childhood Asthma Management Program Research Group. The Childhood Asthma Management Program (CAMP): design, rationale, and methods. Control Clin Trials. 1999; 20:91-120. [PubMed: 10027502]

24. Ng, AY.; Jordan, MI.; Weiss, Y. On spectral clustering, analysis and an algorithm. In: Dietterich, T.; Becker, S.; Ghahramani, Z., editors. NIPS 2001: Proceedings of Advances in Neural Information Processing Systems; 2001 Dec 3-8; Vancouver, British Columbia, Canada. Cambridge: MIT Press; 2001.

25. Tibshirani R, Walther G, Hastie T. Estimating the number of clusters in a dataset via the gap statistic. J R Stat Soc B. 2001; 32:411-23.

26. Boudier A, Curjuric I, Basagaña X, Hazgui H, Anto JM, Bousquet J, et al. 10 year-follow up of cluster-based asthma phenotypes in adults. A pooled analysis of three cohorts. Am J Respir Crit Care Med. 2013; 188:550-60. [PubMed: 23777340]

27. Larsen GL. Differences between adult and childhood asthma. J Allergy Clin Immunol. 2000; 106(suppl):S153-7. [PubMed: 10984396]

\section{Members of the CAMP Research Group}

\section{Clinical centers}

ASTHMA, Inc, Seattle, Washington: Paul Williams, MD (Principal Investigator); Mary V. Lasley, MD (Co-Director); Tamara Chinn, MSN, ARNP (Coordinator). Michele Hinatsu, MSN, ARNP; Clifton T. Furukawa, MD; Leonard C. Altman, MD; Frank S. Virant, MD; Michael S. Kennedy, MD; Stephen Tilles, MD. Jonathan W. Becker, MD (1995-2010); C. Warren Bierman, MD (1992-1997); Dan Crawford, RN (1996-2002); Thomas DuHamel (1991-2004); Heather Eliassen, BA (1996-1999); Babi Hammond (1996-1999); Miranda MacLaren (2008-2011); Dominick A. Minotti, MD (1992-2003); Chris Reagan (19922003); Gail Shapiro (1991-2006, Principal Investigator); Marian Sharpe, RN (1992-1994); Ashley Tatum, MD (2004-2007); Grace White (1991-2007). Timothy G. Wighton, PhD (1994-1998).

Brigham \& Women's Hospital and Harvard Vanguard Medical Associates, Boston, Massachusetts: Anne Fuhlbrigge, MD (Principal Investigator); Anne Plunkett, NP, MS (Coordinator). Nancy Madden, RN, BSN; Susan Anderson; Mark Boehnert, MD; Anita Feins, MD; Amanda Gentile; Natalia Kandror, MD; Kelly MacAulay, MD; Ernestina Sampong; Scott Weiss MD. Walter Torda, MD (Co-Investigator Director, 1993-2003); Martha Tata, RN (1993-2002); Sally Babigian, RN (1997-1999); Peter Barrant, MD (20042007); Linda Benson (1998-2004); Jose Caicedo (1998-1999); Tatum Calder (1998-2001); Christine Darcy (2001-2008); Anthony DeFilippo (1994-2000); Cindy Dorsainvil (19982001); Julie Erickson (1998-1999); Phoebe Fulton (1997); Mary Grace, RN (1994-1996); Jennifer Gilbert (1997-1998); Dirk Greineder, MD (1993-2000); Stephanie Haynes (19931998); Margaret Higham, MD (1996-1998); Deborah Jakubowski (1999); Susan Kelleher (1993-1997); Jay Koslof, PhD (1993-1995); Dana Mandel (1996-1998); Patricia Martin (2001-2003); Agnes Martinez (1994-1997); Jean McAuliffe (1994-1995); Erika Nakamoto (2002-2004); Paola Pacella (1993-1998); Paula Parks (1993-1995); Johanna Sagarin (1998-1999); Kay Seligsohn, PhD (1995-2004); Susan Swords (2003-2005); Meghan Syring (1998-2001); June Traylor, MSN, RN (1996-1998); Melissa Van Horn, PhD (19961999); Carolyn Wells, RN (1993-1995); Ann Whitman, RN (1994-1996). 
The Hospital for Sick Children, Toronto, Ontario, Canada: Hartmut Grasemann, MD (Principal Investigator); Melody Miki, RN, BSN (Coordinator); Melinda Solomon, MD; Padmaja Subbarao, MD. Ian MacLusky, MD, FRCP (Director 1999-2007); Joe Reisman, MD, FRCP(C), MBA (Director, 1996-1999); Henry Levison, MD, FRCP(C) (Director, 1992-1996); Anita Hall, RN (Coordinator, 1993-2007). Yola Benedet (1994-1999); Susan Carpenter, RN (1998-2001); Jennifer Chay (2004); Michelle Collinson, RN (1994-1998); Jane Finlayson-Kulchin, RN (1994-1998); Kenneth Gore, MA (1993-1999); Nina Hipolito, RN (2003-2004); Noreen Holmes, RRT (1998-1999); Erica Hoorntje, RN (2002-2003); Sharon Klassen, MA (1999-2000); Joseé Quenneville, MSc (1993-1995); Renée Sananes, PhD (1993-2004); Christine Wasson, PhD (1999); Margaret Wilson, RN (2001-2002).

Johns Hopkins Asthma \& Allergy Center, Baltimore, Maryland: N. Franklin Adkinson, Jr, MD (Director); Deborah Bull, LPN (Coordinator); Stephanie Philips, RN. Peyton Eggleston, MD (Co-Director, 1991-2004); Karen Huss, DNSc (Co-Investigator, 1991-2004); Leslie Plotnick, MD (Co-Investigator, 1991-1999); Margaret Pulsifer, PhD (Co-Investigator, 1993-2004); Cynthia Rand, PhD (Co-Investigator, 1991-2004). Elizabeth Aylward, PhD (1991-2004), Nancy Bollers, RN (Coordinator, 1993-2004); Kathy Pessaro (2004-2007); Barbara Wheeler, RN, BSN (Coordinator, 1991-1999).

National Jewish Health, Denver, Colorado: Stanley Szefler, MD (Director); Ronina Covar, MD (Medical Director); Harold S. Nelson, MD (Co-Director 1991-2000, Co-Investigator 2000-present); Bruce Bender, PhD (Co-Investigator); Andrew Liu, MD (Co-Investigator); D. Sundström (Coordinator); Melanie Phillips; Michael P. White; Melanie Gleason, PA-C. Kristin Brelsford (1997-1999); Jessyca Bridges (1995-1997); Jody Ciacco (1993-1996); Michael Eltz (1994-1995); Jeryl Feeley, MA (Coordinator, 1992-1995); Michael Flynn (1995-1996); Tara Junk-Blanchard (1997-2000); Joseph Hassell (1992-1998); Marcia Hefner (1992-1994); Caroline Hendrickson, RN (1995-1998; Coordinator, 1995-1997); Daniel Hettleman, MA (1995-1996); Charles G. Irvin, PhD (1992-1998); Alan Kamada, PharmD (1994-1997); Marzena Krawiec, MD (2008-2010); Gary Larsen, MD (CoInvestigator, 2000-2010); Sai Nimmagadda, MD (1993-1996); Kendra Sandoval (19951997); Jessica Sheridan (1994-1995); Joseph Spahn, MD (Co-Investigator 1993-2010); Gayle Spears, PA-C (2003-2007); Trella Washington (1993-1997); Eric Willcutt, MA (1996-1997). We also thank the pediatric allergy/immunology and pulmonary fellows for their participation (Ivan Cardona, MD; Kirstin Carel, MD; Jayna Doshi, MD; Rich Hendershot, MD; Jeffrey Jacobs, MD; Neal Jain, MD; June-ku Brian Kang, MD; Tracy Kruzick, MD; Harvey Leo, MD; Beth Macomber, MD; Jonathan Malka, MD; Chris Mjaanes, MD; John Prpich, MD; Lora Stewart, MD; Ben Song, MD; Grace Tamesis, MD).

University of California, San Diego and Kaiser Permanente Southern California Region, San Diego, California: Robert S. Zeiger, MD, PhD (Director); Noah Friedman, MD (CoInvestigator); Michael H. Mellon, MD (Co-Investigator); Michael Schatz, MD (CoInvestigator); Terrie Long, RN (Coordinator). Travis Macaraeg. Sandra Christensen, MD (2004-2007); James G. Easton, MD (Co-Director, 1993-1994); M. Feinberg (1997-1998); Linda L. Galbreath (1991-2002); Jennifer Gulczynski (1998-1999); Kathleen Harden, RN (Coordinator, 1993-2010); Ellen Hansen (1995-1997); Al Jalowayski, PhD (CoInvestigator, 1991-2005); Elaine Jenson (2004-2007); Alan Lincoln, PhD (Co-Investigator, 
1991-2003); Jennie Kaufman (1994); Shirley King, MSW (1992-1999); Brian Lopez (1997-1998); Michaela Magiari-Ene, MA (1994-1998); Kathleen Mostafa, RN (19941995); Avraham Moscona (1994-1996); Catherine A. Nelle, RN (1991-2005); Jennifer Powers (2001-2003); Elsa Rodriguez (2003-2007); Eva Rodriguez, RRT (1994-2008); Karen Sandoval (1995-1996); Nevin W. Wilson, MD (Co-Director, 1991-1993).

University of New Mexico, Albuquerque, New Mexico: Hengameh H. Raissy, PharmD (Director); Aaron Jacobs (Co-Investigator); H. William Kelly, PharmD (Director, 19982011); Mary Spicher, RN (Coordinator). Christina Batson; Michelle Harkings, MD; Katie McCallum. Robert Annett, PhD (Co-Investigator, 1993-2004); Teresa Archibeque (19941999); Naim Bashir, MD (Co-Investigator, 1998-2005); H. Selda Bereket (1995-1998); Marisa Braun (1996-1999); Carrie Bush (1995-1999); Shannon C. Bush (2002-2007); Michael Clayton, MD (Co-Investigator, 1999-2001); Angel Colon-Semidey, MD (CoInvestigator, 1997-2000); Sara Devault (1993-1997); Anna Esparham (2004-2007); Roni Grad, MD (Co-Investigator, 1993-1995); David Hunt, RRT (1995-2004); Jeanne Larsson, RN (1995-1996); Sandra McClelland, RN (Coordinator, 1993-1995); Bennie McWilliams, MD (Co-Investigator, Director, 1992-1998); Elisha Montoya (1997-2000); Margaret Moreshead (1996-1999); Shirley Murphy, MD (Co-Investigator, 1992-1994); Barbara Ortega, RRT (1993-1999); David Weers (1997-1998); Jose Zayas (1995-1996).

Washington University, St Louis, Missouri: Robert C. Strunk, MD (Director); Leonard Bacharier, MD (Co-Investigator); Denise Rodgers, RPFT (Coordinator). Ellen Albers, RN, CNS-P, MSN (1997-1999); Gregg Belle, MA (1996-2001); Gordon R. Bloomberg, MD (Co-Investigator, 1994-2007); W. Patrick Buchanan (1998-2001); Mary Caesar, MHS (1993-1996); James M. Corry, MD (Co-Investigator, 1994-2004); Karen DeMuth (20062007); Marisa Dolinsky, MA (1996-2001); Edwin B. Fisher, PhD (1993-2001); Stephen J. Gaioni, PhD (1993-2001); Emily Glynn, RN, MSN, CSPNP (1993-2001); Bernadette D. Heckman, MA (1996-2001); Debra Kemp, RN, BSN (1994-2001); Lila Kertz, MSN, RN, CPNP (2005-2007); Claire Lawhon (1994-2003); Valerie Morgan, RRT (2000-2004); Cynthia Moseid (1997); Tina Oliver-Welker, CRTT (1994-2007); Diana Richardson (19941997); Elizabeth Ryan, PhD (1994-1997); Sharon Sagal, MD (1996-2001); Thomas F. Smith, MD (1993-1998); Susan Sylvia, PhD (1994-1997); Carl Turner (1995-1997); Deborah K. White, RPFT, RRT (1994-2007).

\section{Resource centers}

Data Coordinating Center, Johns Hopkins University, Baltimore, Maryland: James Tonascia, PhD (Director). Patricia Belt; Karen Collins; Betty Collison; John Dodge; Michele Donithan, MHS; Cathleen Ewing; Rosetta Jackson; Patrick May, MS; Jill Meinert; Girlie Reyes; Michael Smith; Alice L. Sternberg, ScM; Mark L. Van Natta, MHS; Annette Wagoner; Laura Wilson, ScM; Robert Wise, MD; Katherine Yates, ScM.

Project Office, National Heart, Lung, and Blood Institute, Bethesda, Maryland: Virginia Taggart, MPH (Project Officer); Lois Eggers; James Kiley, PhD; Howard Moore; Gang Zheng, PhD. Paul Albert, PhD (1991-1999); Suzanne Hurd, PhD (1991-1999); Sydney Parker, PhD (1991-1994); Pamela Randall (1992-2003); Margaret Wu, PhD (1991-2001). 


\section{Committees}

Data and Safety Monitoring Board: Michelle Cloutier, MD (Chair); John Connett, PhD; Leona Cuttler, MD; Frank Gilliland, MD, PhD. Clarence E. Davis, PhD (1993-2003); Howard Eigen, MD (1993-2009, Chair); David Evans, PhD (1993-2007); Meyer Kattan, MD (1993-2007); Rogelio Menendez, MD (1993-2007); F. Estelle R. Simons, MD (19932007); Sanford Leikin, MD (1993-1999).

Steering Committee: Robert Strunk, MD (Study Chair); N. Franklin Adkinson, MD; Robert Annett, PhD (1992-1995, 1997-1999); Bruce Bender, PhD; Mary Caesar, MHS (19941996); Reuben Cherniack, MD (Study Chair 1993-2007); Ronina Covar, MD; Thomas R. DuHamel, PhD (1992-1994, 1996-1999); Anne Fuhlbrigge, MD; Hartmut Grasemann, MD; H. William Kelly, PharmD; Henry Levison, MD (1992-1996); Alan Lincoln, PhD (19941995); Ian MacLusky, MD (1999-2006); Bennie McWilliams, MD (1992-1998); Curtis L. Meinert, PhD; Sydney Parker, PhD (1991-1994); Hengameh H Raissy, PharmD; Joe Reisman, MD, FRCP(C), MBA (1991-1999); Denise Rodgers; Kay Seligsohn, PhD (19961997); Gail G. Shapiro, MD (1991-2006); Marian Sharpe (1993-1994); D. Sundström (1998-1999); Stanley Szefler, MD; Virginia Taggart, MPH; Martha Tata, RN (1996-1998); James Tonascia, PhD; Scott Weiss, MD, MS; Barbara Wheeler, RN, BSN (1993-1994); Paul Williams, MD; Robert Wise, MD; Robert Zeiger, MD, PhD. 


\section{Clinical implications}

Childhood asthma is heterogeneous. The current cluster analysis suggests that heterogeneous phenotypic clusters of asthmatic children remain stable over time, even after treatment with different medical therapies. 
A

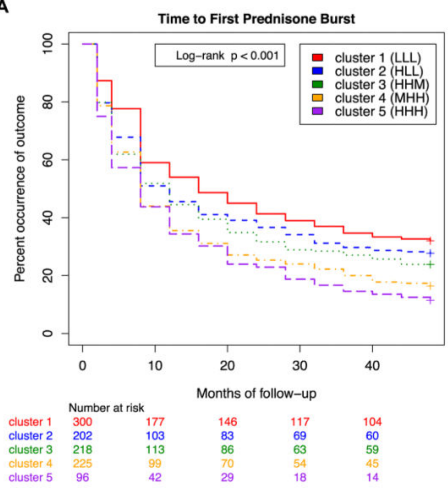

B

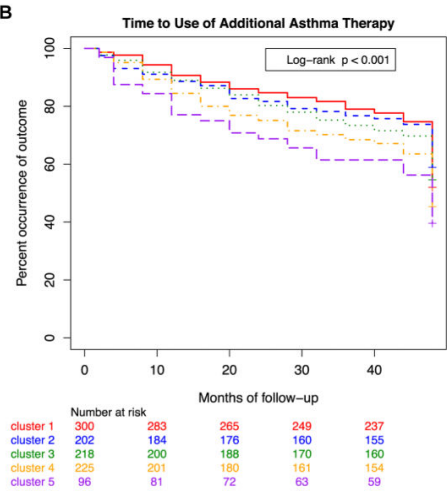

FIG 1.

Kaplan-Meier plots by cluster of the cumulative probability of a first course of prednisone (A) or initiation of additional asthma controller therapies (beclomethasone or other; B) during the 4-year follow-up period of the CAMP trial. 

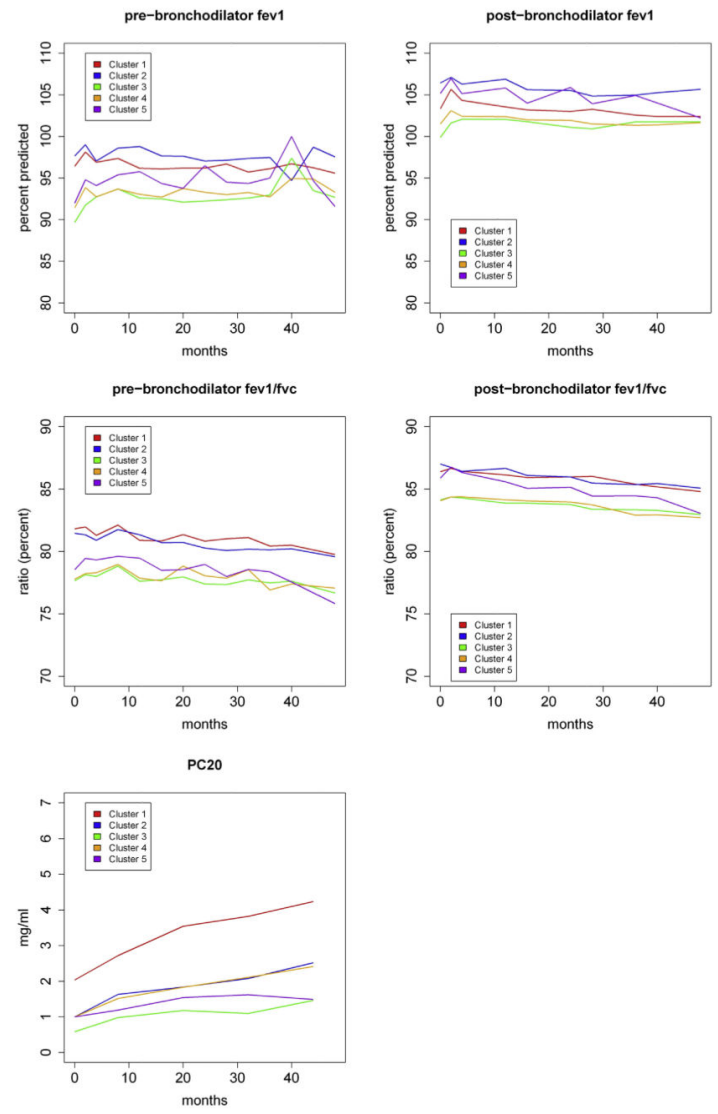

FIG 2.

Mean pulmonary function measurements for each phenotypic cluster evaluated over 48 months of follow-up. $P$ values for between-cluster differences among all longitudinal measures were less than .0001 , as calculated by using linear mixed-effects models. 

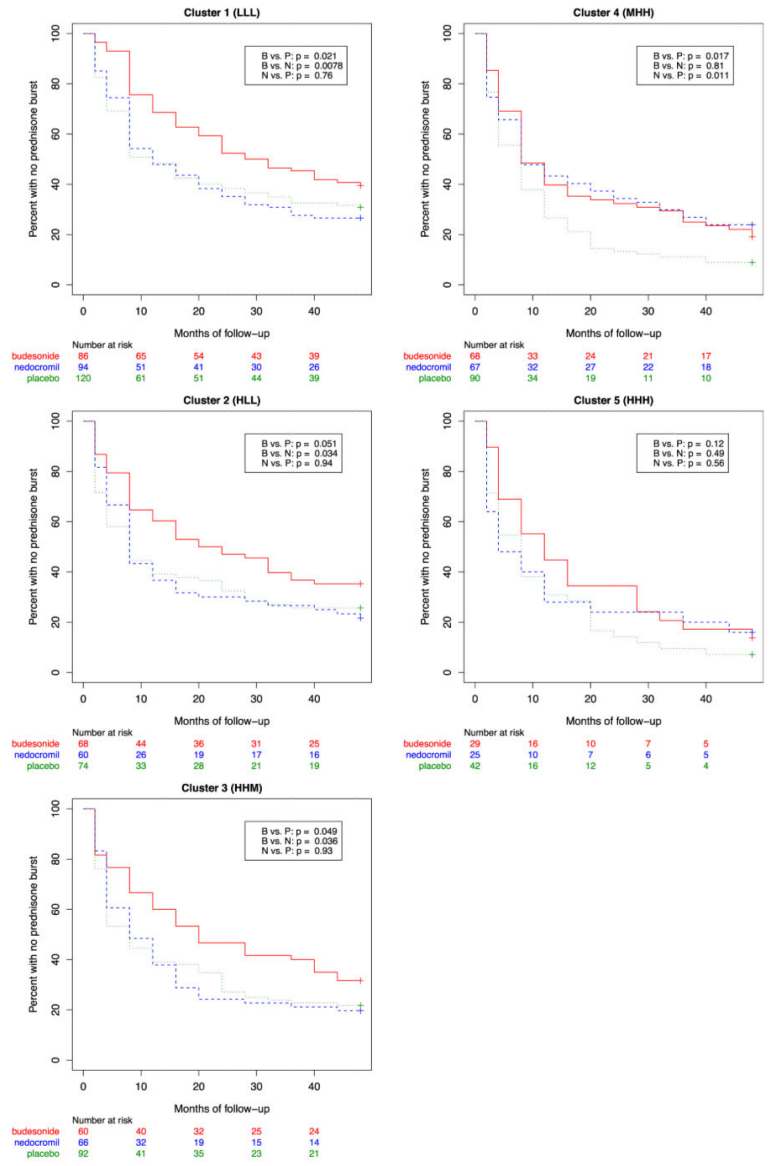

FIG 3.

Kaplan-Meier estimate by treatment group of the cumulative probability of prednisone use during 4 years of follow-up stratified by phenotypic cluster. $B$, Budesonide; $N$, Nedocromil. 


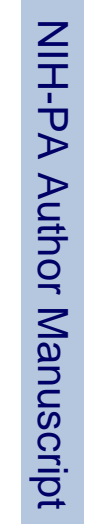

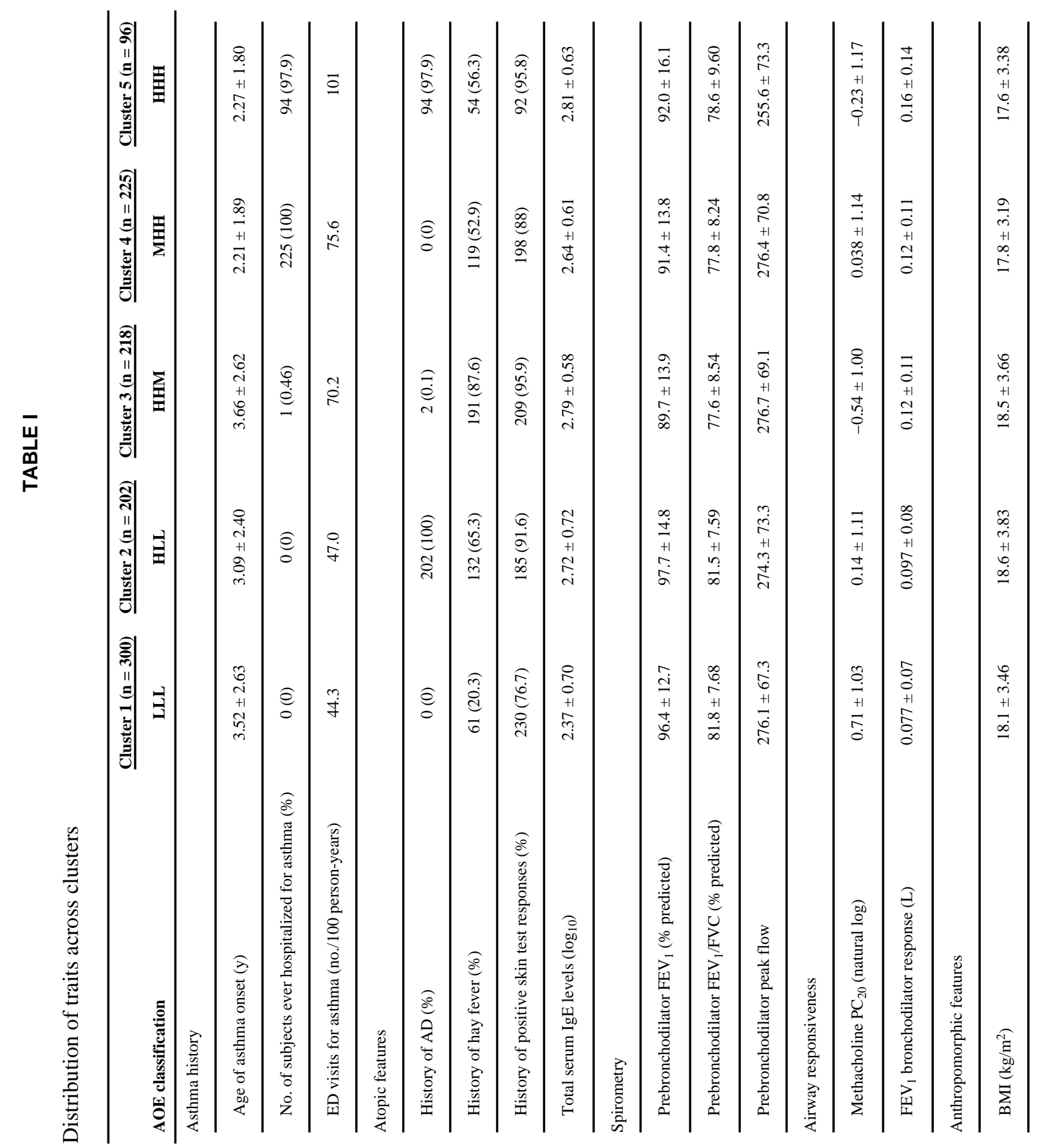




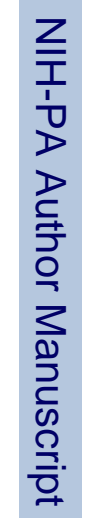

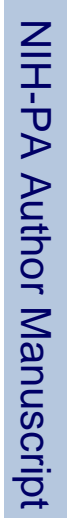

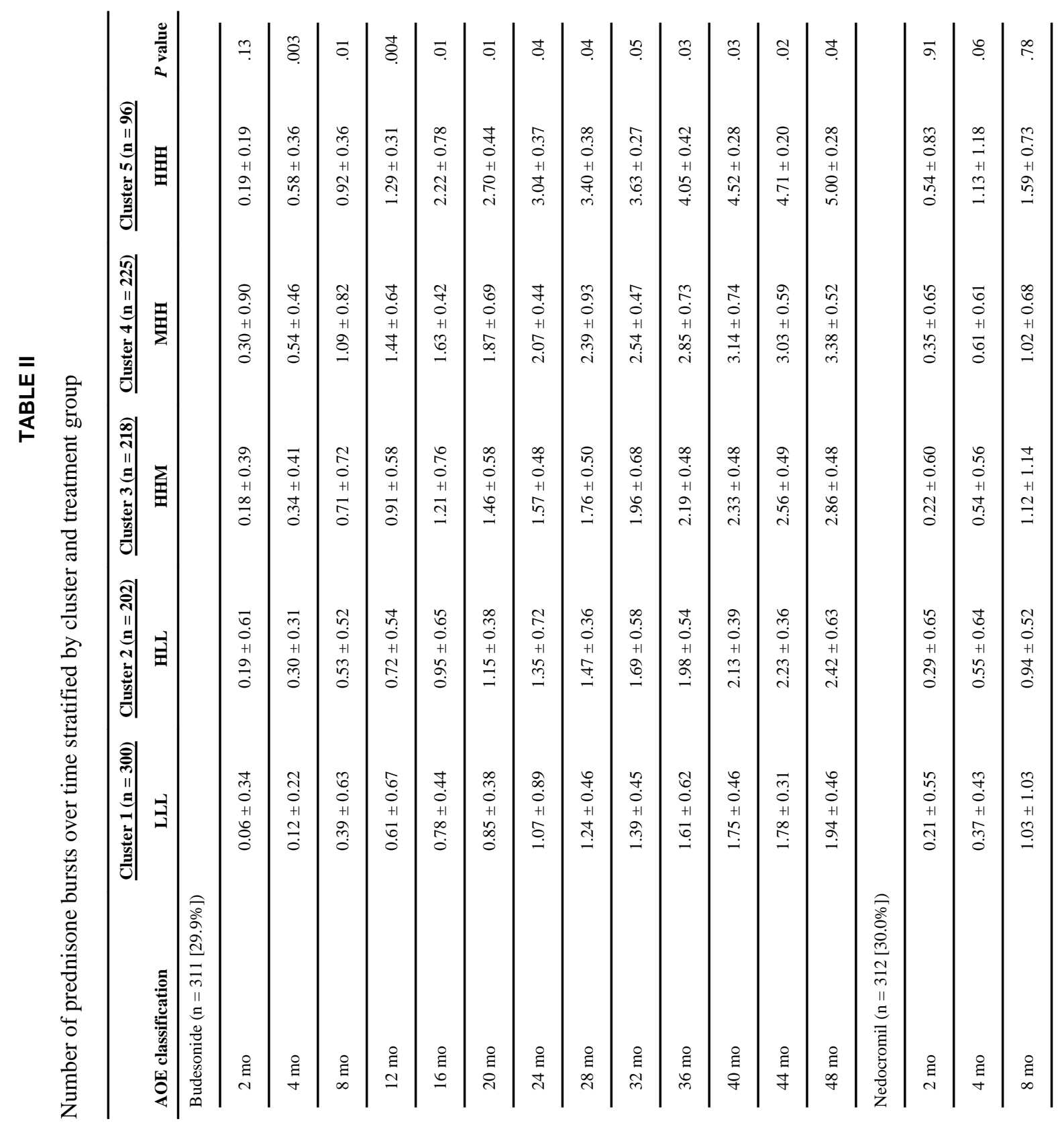




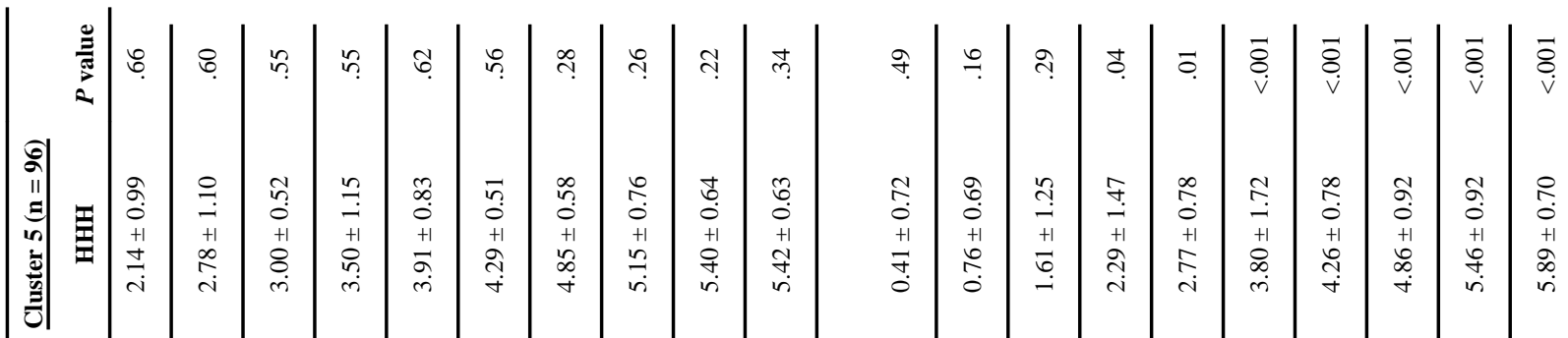




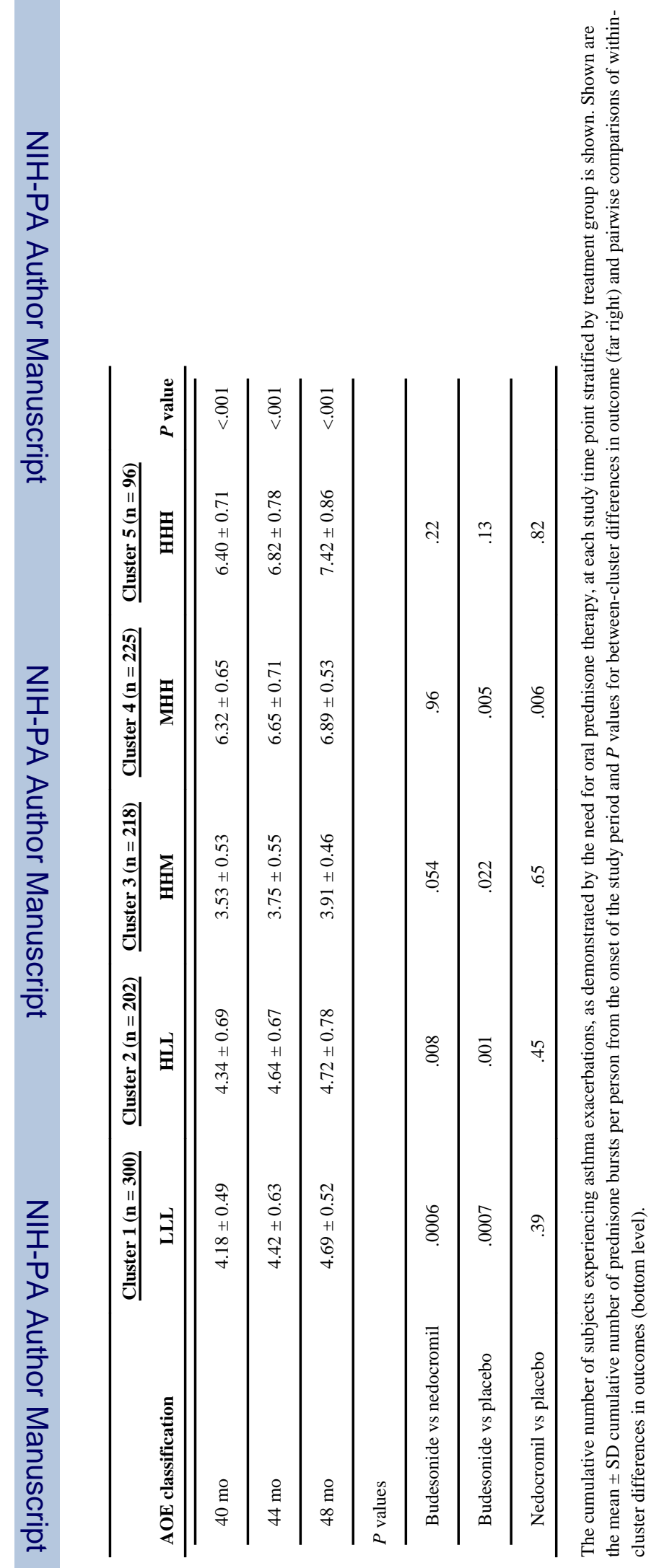




\section{TABLE III}

Comparison of study design and results from independent asthma phenotype clustering analyses

\begin{tabular}{|c|c|c|c|}
\hline & CAMP (current study) & SARP childhood study & SARP adult study \\
\hline Sample size & 1041 & 161 & 726 \\
\hline Age distribution (y) & $5-13$ & $6-17$ & $12-80$ \\
\hline Percentage non-Hispanic white & 68 & 39 & 64 \\
\hline Inclusion criteria & $\begin{array}{c}\text { Dx, AHR, BDR } \\
\text { No active symptoms }\end{array}$ & $\begin{array}{c}\text { Dx, AHR, BDR } \\
\text { No active symptoms }\end{array}$ & Dx, nonsmokers \\
\hline ICS at time of evaluation & No & Yes $\times 6 \mathrm{mo}$ & Yes \\
\hline Spectrum of severity at enrollment & Mild to moderate & Mild to severe & Mild to severe \\
\hline Variables included in model & 18 & 12 & 34 \\
\hline No. of clusters & 5 & 4 & 5 \\
\hline \multicolumn{4}{|l|}{ AOE cluster subtypes } \\
\hline 1. LLL & Cluster $1(28.8 \%)$ & Cluster $1(29.8 \%)$ & Cluster $1(15.2 \%)$ \\
\hline Descriptor & $\begin{array}{l}\text { Mild asthma with a low atopic } \\
\text { burden }\end{array}$ & Late onset, normal lung function & $\begin{array}{l}\text { Young female subjects with } \\
\text { atopic asthma and normal } \\
\text { lung function }\end{array}$ \\
\hline Age of asthma onset (y) & 3.52 & 6.08 & \\
\hline Total serum IgE (kU/L) & 234 & 105 & 141 \\
\hline $\mathrm{AD}$ & $0 \%$ & $50 \%$ & \\
\hline Pre-BD $\mathrm{FEV}_{1} / \mathrm{FVC}$ ratio & $0.82 \pm 0.8$ & $0.82 \pm 0.11$ & $0.78 \pm 0.1$ \\
\hline Exacerbation rate (rank) & Lowest & Lowest & Lowest \\
\hline 2. HLL & Cluster $2(19.4 \%)$ & Cluster $2(32.3 \%)$ & Cluster $2(44.2 \%)$ \\
\hline Descriptor & $\begin{array}{l}\text { Atopic with preserved lung } \\
\text { function }\end{array}$ & $\begin{array}{l}\text { Early onset, atopic, normal lung } \\
\text { function }\end{array}$ & $\begin{array}{l}\text { Older female subjects with } \\
\text { atopic asthma and normal } \\
\text { lung function }\end{array}$ \\
\hline Age of asthma onset (y) & 3.09 & 2.5 & \\
\hline Total serum IgE (kU/L) & 524 & 405 & 125 \\
\hline $\mathrm{AD}$ & $100 \%$ & $56 \%$ & \\
\hline Pre-BD $\mathrm{FEV}_{1} / \mathrm{FVC}$ ratio & $0.81 \pm 0.8$ & $0.79 \pm 0.09$ & $0.74 \pm 0.1$ \\
\hline Exacerbation rate (rank) & Second lowest & Second lowest & Second lowest \\
\hline 3. HНM & Cluster $3(20.9 \%)$ & Cluster $3(19.9 \%)$ & Cluster $4(16.5 \%)$ \\
\hline Descriptor & High obstruction, severe AHR & $\begin{array}{c}\text { Early onset, atopic, mild airflow } \\
\text { limitation }\end{array}$ & $\begin{array}{c}\text { Childhood-onset atopic } \\
\text { asthma, severe obstruction, } \\
\text { high BDR }\end{array}$ \\
\hline Age of asthma onset (y) & 3.66 & 1.2 & \\
\hline Total serum $\operatorname{IgE}(\mathrm{kU} / \mathrm{L})$ & 616 & 216 & 132 \\
\hline $\mathrm{AD}$ & $0.1 \%$ & $47 \%$ & \\
\hline Pre-BD FEV $\mathrm{FVC}_{1} / \mathrm{FV}$ ratio & $0.78 \pm 0.8$ & $0.72 \pm 0.10$ & $0.64 \pm 0.1$ \\
\hline Exacerbation rate (rank) & Third lowest & Third lowest & Third lowest \\
\hline 4. МНH & Cluster $4(21.6 \%)$ & Not represented & Cluster $5(16.0 \%)$ \\
\hline
\end{tabular}




\begin{tabular}{|c|c|c|c|}
\hline & CAMP (current study) & SARP childhood study & SARP adult study \\
\hline Descriptor & $\begin{array}{l}\text { Low atopy, high obstruction, high } \\
\text { exacerbation }\end{array}$ & & $\begin{array}{c}\text { Childhood-onset atopic } \\
\text { asthma, severe obstruction, } \\
\text { low BDR }\end{array}$ \\
\hline Age of asthma onset (y) & 2.21 & & \\
\hline Total serum IgE $(\mathrm{kU} / \mathrm{L})$ & 436 & & 98 \\
\hline $\mathrm{AD}$ & $0 \%$ & & \\
\hline Pre-BD FEV $/$ FVC ratio & $0.78 \pm 0.08$ & & $0.57 \pm 0.1$ \\
\hline Exacerbation rate (rank) & Second highest & & Second highest \\
\hline 5. НHH & Cluster $5(9.2 \%)$ & Cluster $4(18.0 \%)$ & Cluster $3(8.13 \%)$ \\
\hline Descriptor & Exacerbation & $\begin{array}{l}\text { Early onset, atopic, advanced } \\
\text { airflow limitation }\end{array}$ & $\begin{array}{l}\text { Older women, high BMI, low } \\
\text { atopy, low BDR }\end{array}$ \\
\hline Age of asthma onset (y) & 2.68 & 1.6 & \\
\hline Total serum IgE $(\mathrm{kU} / \mathrm{L})$ & 645 & 361 & 54 \\
\hline $\mathrm{AD}$ & $97.9 \%$ & $72 \%$ & \\
\hline Pre-BD FEV $/$ FVC ratio & $0.79 \pm 0.09$ & $0.73 \pm 0.10$ & $0.74 \pm 0.1$ \\
\hline Exacerbation rate (rank) & Highest & Highest & Highest \\
\hline
\end{tabular}

$A H R$, Airway hyperresponsiveness; $B D$, bronchodilator; $B D R$, bronchodilator response; ICS, inhaled corticosteroid; $D x$, diagnosis. 